\title{
METHODS OF DIFFUSION OF INNOVATION WITHIN SMALL SEAFOOD ENTERPRISES
}

\author{
K. S. Chaqravand*, M. O. N. Abadi, \\ School of agriculture, Science and Research branch, Islamic Azad University, Tehran, Iran
}

Published online: 19 July 2016

\begin{abstract}
If any technical and technological achievement, don't spread among whole system, no economical long term benefit will be achieved for industry. In recent years, all developed industrial countries (some developing countries as well), followed many plans and political strategies with aim of improving technology diffusion.

In present essay, technology level enhancement of small seafood enterprises is studied based on technology diffusion. New technologies attraction in small enterprises causes competition especially in small sea food enterprises in internal markets (considering lack of water resources). Therefore, to accomplish such thing, diffusion of new technologies is needed. So, four groups of technology diffusion plan were extracted for small and medium businesses. Those are training programs, motivational program, financial support of research program and communication plan and technical cooperation.
\end{abstract}

Keywords: innovation diffusion, small seafood enterprises, new technologies

Author Correspondence, e-mail: kayvanshoja@gmail.com

doi: http://dx.doi.org/10.4314/jfas.v8i2s.159

\section{INTRODUCTION}

Innovation management is a complex process and key element in recognizing opportunities and new capabilities, reducing risk-taking in organization, being responsible to functional 
management and change management, having strategic thinking, imagining organization in future and documenting innovation process. It needs effective power in planning and coordinating professionals, executive structure of organization and information about needs of industry and community. It also enhanced globalizing competition process on resources and market in a way that, in many dimensions, Organizations compete on insensible properties like human resources. Competition on sales market is increased by offering better products. One consequence of such competition is organization's effort to internalize innovation culture in working environment. Individual innovation of employees in working environment is basic element of enhancing performance of each organization. Innovation is a complex process that includes a three stages process of problem understanding and offering new solutions, improving novel ideas and finding rule to defend it and finally, presenting model or experimental sample to execute ideas and solutions in a group or organization. In 1997 Teslak, Far and Cline found that innovative Organizations have similar cultures. They encourage people to experience. They appreciate new experience. By considering all aspects, they reward successes and failures. They experienced from mistakes. They control environment closely. They respond to changes in the best way and in shortest time.

Anyway, innovation is something that is required for any organization. So it should be internalized. Whenever supreme managers and policy makers of organization do not believe innovation as a necessary activity, no progress will be achieved. Establishing research and innovation centers in organization could facilitate innovation and creativity. Another effective criterion on innovation in organization is the environment of that organization. Environment includes factors like sales market, financial sources, human resources, politics, culture and safety. Davoud et Al 2011, have done survey study on some big industrial companies. They found that culture of innovation acceptance is the most important reason of innovation in an organization. Vahidzadeh 2004 considered the reason of failure of many production companies as inadequate investment and their denial to innovation, weak relations of managers and lack of organizational discipline.

Nowadays, innovation to be successful in work is essential element. However there are many people that don't understand the value and management method of innovation. 
Small food industries especially seafood enterprises, face problems like manager's lack of attention to innovation, manager's unfamiliarity with new technologies, inadequate education, weakness in innovation management, lack of investment, lack of professionals, lack of training, not accessing to research and development sources. To solve such problems, Hoseini and Soltani proposed multi-channel communicative learning model. This model is proposed on level of economic business that are the most important producers of economic innovation in society. It could start in everywhere. The result could be innovation in product, process, or finding new market and new procedure to organize production units. Innovation process is a reply to effective factors, or limiting ones. So there is a close environment that includes actors and other organizations that influenced on innovation process of companies. Such small environment itself is located in a one wider complex, a macro environment.

\section{Importance and necessity of expanding new technologies in small seafood industries}

Technological improvements are determining factor in change of community. Technology enhancement is recognized as the base of development in each country. Application of sciences and technology is effective in growth of society. Such effect leads to a new idea, method or experience or leads to new product, technic and activity. Technology enhancement is a necessary criterion in fast social-economic development of countries. Considering technology as the main variable of development, innovation enhancement and diffusion works as motive force of socialeconomic development. Technology expansion in terms of technology management has a wide range of meaning. Technology diffusion is a process in which innovation and existed technological knowledge transfer to members of a social society by definite channels during time.

According to such definition, technology expansion has four components: 1.Innovation2.diffusion3.time4.system

The effect of technology expansion on national development is more than transfer of technology. In technology transfer, profit goes to only one business. However in technology diffusion, more than one business, gain a benefit. On the other hand, technology development in a specific case has no important effect on a country's economic. However, if technology diffusion happened in all country, it has no significant effect on economic development. Technology diffusion is the interest of government and big governmental systems. Development on national level is 
important to them. Most of smaller enterprises prefer to use developed technologies in the past and according to their capabilities. Smaller enterprises are more dependent to technology sources rather than bigger enterprises. They have no access to technologies due to their worse condition in production and their reliance on external financial sources. On enterprise level, managers of smaller companies might face problems like time, cost, technical abilities, hardware and software technologies, process supervision, training or management methods. Even when small seafood enterprises have good abilities, processes or classical products, they might be useless because of technology development. Small enterprises usually don't provide official training for their employees. However training institute is not always responsible of their needs. Universities insist on research and training or cooperate with bigger enterprises to attract new technologies and financial supports.

Recently, economic challenges created severe problems for small seafood enterprises. In such critical condition, companies' abilities in maintaining innovative process could lead to a main source of competition advantages. The importance of new technologies is accepted by managers, policy makers and researchers. Innovations usually are created to respond to technological or organizational challenges. So innovation is first created in companies that are mostly under pressure to provide answer to these challenges.

From such perspective, an assistance to small industrial companies to gain stability in such critical conditions would be making policies that support innovations. First step in proper policy making to support innovation in small and medium economic enterprises is reviewing factors that have effect on innovative efforts of companies; and also reviewing the process of such effects.

Generally, innovation means new commodity production, process application, knowledge, technology or new services. Technologic innovation as a specific kind of innovation is defined by Bjorn et al: technologic innovation is the use of new or enhanced technologies in organization. Technology includes various information communication technologies and also technical technologies used in a certain industry.

Some sources differentiate between two kinds of innovation which are radical and gradual innovations. Such resources are Radaz\& Bozic which consider radical innovation as a kind of 
innovation that is new to a company. They consider gradual innovation as less new to a company that includes partial changes in available technologies of a company.

In studies done by Bozic \& Radas in 2009, effective factors on innovative activities of businesses in economies in translation were analyzed. At time of reviewing innovative index, researcher differentiates between new products with gradual innovation and radical innovations. Then they found that these two innovations are supported by various policies. Cooperation with other companies or organizations has positive effect on innovation of products and process. Having relationship with universities and research centers has only effects on product. Although cooperation of industry and university were so limited and faces many problems, it will cause positive results and encourage policy makers.

Technology improvement is a determinative factor in the evolution of human societies and technology enhancement is a basic element in every country. Technology improvement and innovation enables economic institutes to achieve competition abilities. This question that whether economic institutes are innovative or not depends on different factors. That is the subject of different resources like present one.

Roozbahani studies in 2009 regarding effective factors on technologic innovation in early returns businesses shows a meaningful and positive relationship between innovation in product, innovation in process and technologic innovation. Such research indicated that market size has the most effect on technologic innovation. Other involved factors are research and development center, training courses, relation with research institutes, policies and regulations and company's features

Koellinger studies in 2008 showed that acceptance of new technologies will causes increase in innovation in process or product.

Mohamadinezhad in 206, in his essay under the name of studies on performance and technology improvement in the poultry industry of Iran founded that technology includes $80 \%$ of improvement in performance. Company's criteria's and manager's characteristics have effect on technologic improvement.

Tomlinsn in 2010 studied relations of cooperation and innovation in UK industries. They found positive and meaningful relationship between companies and innovative performance. Also, relation between innovative performance, company size, research and development center, 
company age, cooperation with raw material suppliers and cooperation with buyers and competitors have been confirmed.

Zeng et al in 2010 studied relationship between cooperative networks and innovative performance of early returns enterprises in china. Results indicated that cooperation with governmental institutes has no effect on innovative performance of companies. Available policies of government have no effect on innovative performance of companies and official affairs were considered as obstacle. Positive and meaningful relationship between close cooperation with customers and suppliers had positive and meaningful influence on innovative performance of companies.

\section{Methods of enhancing abilities to attract new technologies in small seafood industries}

Small and medium companies are different in their abilities and motivations to attract and develop new technologies. Small portion of small seafood industries have strong internal technological development abilities such as professional managers and employees. They might be pioneer in industry and market. Most of small seafood industries, follow technology with a compound of internal abilities. Other small industries pay no attention to new technologies. Most methods of technology diffusion focused on the first and the second groups of companies. Possibly, we can consider an important role in third group for technics like management, production and methods of edited employees. Such technics could enhance institutes with low cost.

Technology diffusion policies basically are not made for completely new structures. They are made for enhancing performance and diffusionand leads to more effective cooperation. Executions that government follow to increase attraction of seafood industries require infrastructure like social and work ones.

\section{Effective factors on technology diffusion in small seafood industries in Iran}

\section{a. Training program and enhancing knowledge}

Offering especial training to managers and entrepreneurs by providing training workshop and establishing permanent relationship between them and expert consultant.

Establishing and developing Information networks. Without such facilities, a considerable part of opportunities, abilities of companies will spend for gathering information.

\section{b. Motivational plans and financial support}


Offering long-term loans with low profit rate, bank guarantees regarding primary and current costs of new technology acceptance. Tax rebate to the amount of $70 \%$ for small and medium size companies that were successful in registering new patent, innovation in new production, reducing damages and designing new methods.

Tax exemption, customs exemption to attract big investment companies

Establishing private institutes of supplying capital and internalizing small seafood industries and their participation in investment and profit.

Insuring self-employed people's capital in new technologies against economic fluctuations like bankruptcy, plans and activities failure or any other unexpected events

\section{c. Research program and $R \& D$ cooperation}

To reduce the gap between development and application of technology, various joint research mechanism between private and governmental departments. Such methods will decrease commercialization of innovative technologies and will focus on needs and main opportunities. Exchanging staff within small seafood governmental industries and on international level, in order to learn new technologies and participating in joint researches to supply professional staff Establishing and developing non production small and medium size companies. Such companies are active in fields of research, laboratory, and test and control room, industrial consultation, designing and planning.

Establishing R\&D centers for small and medium enterprises with the aim of using science centers and scientists.

\section{CONCLUSION}

According to obstacles on development of small and medium size enterprises of countries (such a financial obstacles in getting loan, offering bank bail in return, huge cost of importing technology and lack of access to information like marketing ,new technologies, innovation, new technology production and etc.) and their problems in competing with local and international market, government and specifically small industries and industrial states as policy makers for small and medium enterprises, have to take actions to remove such limitations and to improve the capacity of new technologies. An example of such action is assistance in technology diffusion. Accordingly, four groups of technology diffusion programs were extracted for small 
and medium enterprises. These programs were trainingprogram and enhancing knowledge, motivational plans and financial support, and research program, communication plans and technical cooperation. Also, an important factor in technology diffusion and development is that the government pays attention to the mechanism of technology diffusion in industry. Government should endeavor in forming a stable and systematic condition in line with technology diffusion in industry and exit from random and subjective condition. So, it is necessary to use professionals in technology on level of policy making and industrial planning.

\section{Suggestions}

According to correlation and cause and effect relations between technological innovation and other innovation in product and process, it is suggested that in order to enhance technological innovation, there should be attention to development of innovation in products and processes in studied companies. Based on results, more experienced companies in the field of technology, were more innovative. As the studied companies were rather new established and had less experience, it is suggested that more attention be paid regarding support of technological innovation in a manner that inadequate experience and background have less negative effect on technological innovation, radical kind. For the purpose of supporting Research and development units, it is suggested that consultant and training services be provided to them. According to founded results, there is a need of enhancing quality and quantity of training courses for managers of small seafood enterprises. It is recommended that group work will be established and more training courses will be arranged and performed with better quality.

\section{REFERENCES:}

- Malihi,1997. Management of innovation in the industry. First Conference of Industries and Mines R \& D centers. Community Research and Development Center of Industries and Mines. Tehran.

- Khosravian,G. and Atashparvar. Relationship between organizational climate and culture of innovation in the field of executive staff Sepahan Cement Company. Knowledge and research in applied psychology. 2009, 41:118-103 
- Alirezaee, T. Strategies for strengthening innovation and development in the organization. Journal of management and human resources in the petroleum industry, 2008, 96: 67-3.

- Hadipour, Pathology of innovation in the organization. Monthly journal of Tehran University. 2008, 67: 43 to 41

- Aqadavoud, H. H. Factors affecting organizational innovation among executives (senior managers of Isfahan Province Telecommunications). Social Sciences Journal of Islamic Azad University, Shoushtar Branch 2010, 4(11): 170 to 127.

- Vahidzadeh. Pathology of Management in production cooperatives (industrial). Cooperatives, 2004, 159: $64-60$.

- Hosseini and Soltani 2011. Agricultural Innovation Management. Tehran: SID, teacher training unit.

- Roozbahani 2009. Factors affecting the technological innovation in small and medium enterprises -Thesis of Master Degree in Technology Management, Islamic Azad University, Science and Research Branch of Tehran

How to cite this article:

Chaqravand S K, Abadi N O M. Methods of diffusion of innovation within small seafood enterprises. J. Fundam. Appl. Sci., 2016, 8(2S), 1957-1965. 